\title{
The X-Files: uma análise das estratégias de social TV do perfil @thexfiles
}

\section{The X-Files: an analysis of the social TV strategies of the @thexfiles profile}

\author{
Daiana Sigiliano ${ }^{1}$ \\ Gabriela Borges ${ }^{2}$
}

Resumo: A social TV marca a convergência da experiência televisiva com as novas mídias. O fenômeno se refere ao compartilhamento de conteúdos por intermédio das redes sociais e dos aplicativos de segunda tela de maneira síncrona ao fluxo televisivo. A partir desse contexto, este artigo tem o objetivo de refletir sobre as ações de social TV adotadas pela Fox durante a 10 temporada de The X-Files. Analisamos as postagens da página (@thexfiles) gerenciada pelo canal no Twitter a fim de entender como contribuem para o aprofundamento e a compreensão do universo ficcional da série. Concluímos que as estratégias de engajamento da emissora reforçam o laço social, estimulam a participação dos telespectadores interagentes e ampliam os arcos narrativos de The X-Files.

Palavras-chave: social tv; televisão; Twitter; The X-Files

\begin{abstract}
The social TV marks the convergence of television experience with social media. The phenomenon refers to content sharing through social networks and second screen apps simultaneously to television broadcasting. In this context, this article aims to discuss the features explored by Fox during The X-Files 10th season to engage the interacting viewers with social TV. We analysed the dialogue between the fictional universe of the series and the backchannel through a monitoring of @thexfiles profile postings on Twitterduring the exhibition of series episodes.
\end{abstract}

Keywords: social tv; television; Twitter; The X-Files

1 Universidade Federal de Juiz de Fora. Juiz de Fora, MG, Brasil. E-mail: daianasigiliano@gmail.com 2 Universidade Federal de Juiz de Fora. Juiz de Fora, MG, Brasil. E-mail: gabriela.borges@ufjf.edu.br 


\section{Introdução}

Apesar de ser um fenômeno recente, as discussões sobre a social TV começaram no início dos anos 2000. Conforme ressalta Fechine (2016), as reflexões inicialmente estavam ligadas ao âmbito da televisão interativa digital, conhecida como iTV. Posteriormente, com a popularização das redes multimodais e dos dispositivos móveis, a social TV passou a ser designada para descrever a convergência entre a televisão e as mídias sociais (PROULX e SHEPATIN, 2012). Nesse contexto, o fenômeno se refere ao compartilhamento de conteúdos (comentários, memes, vídeos, montagens, fotos etc.) através das redes sociais (Twitter, Facebook, Snapchat, Instagram etc.) e dos aplicativos de segunda tela ${ }^{3}$ (TV Showtime, TV Tag, Viggle etc.) de maneira síncrona ao fluxo televisivo (PROULX e SHEPATIN, 2012; BORGES e SIGILIANO, 2016).

Entretanto, apesar de se configurar em ambiente de convergência, a social TV é caracterizada por aspectos que sempre integraram a experiência televisiva. Segundo Wolton (1996), a TV é um objeto de conversação, pois, independente da temporalidade, o meio pauta assuntos e estimula o diálogo entre os telespectadores. O autor afirma que "[a] televisão é um formidável instrumento de comunicação entre os indivíduos. O mais importante não é o que se vê, mas o fato de se falar sobre isso" (WOLTON, 1996, p. 16). A capacidade do meio de instigar o debate vai além da constituição de uma esfera pública. De acordo com Summa (2011, p. 9), “[...] a televisão não é apenas uma grande influência sobre a sociedade, mas uma força motriz para a interação social ${ }^{4 "}$ (tradução nossa). O próprio processo de recepção do meio facilita a interlocução dos telespectadores:

[...] a TV, ao contrário do cinema, admite que se converse enquanto a programação é exibida. Se um espectador falar em voz alta no cinema, provavelmente será advertido por algum vizinho de assento. Com

\footnotetext{
3 Refere-se à interação paralela e sincronizada com a experiência televisiva através de dispositivos móveis (PROULX e SHEPATIN, 2012).

4 "[...] television is not only a major influence on society, but also a driving force for social interaction".
} 
a televisão, ao contrário, é comum que se façam comentários durante a exibição (CANNITO, 2010, p. 59).

Porém, na social TV, os comentários, que antes ficavam restritos à sala de estar, ao círculo de amigos, aos familiares e aos colegas de trabalho, são transpostos para as redes sociais e para os aplicativos de segunda tela, possibilitando novas apropriações, subversões e amplificações do watercooler. ${ }^{5}$ Nesse sentido, a intermediação da conversação por plataformas digitais ressignifica a interlocução dos telespectadores.

Outro aspecto da ambiência televisiva que ganha novos desdobramentos na social TV é a experiência coletiva. Segundo Wolton (1996, p. 15), a televisão é capaz de "reunir indivíduos e públicos que tudo tende a separar e oferecer-lhes a possibilidade de participar individualmente de uma atividade coletiva”. O fator agregador da televisão, essa conexão com a pluralidade que permeia o meio, está relacionada ao que Anderson (2008) conceitua como comunidade imaginada. As discussões do autor nos ajudam a refletir como o consumo coletivo de um mesmo produto cultural possibilita a construção de laços comunitários e identitários. A comunidade imaginada formada a partir da exibição de um programa televisivo evoca, mesmo que de maneira fantasiosa, a noção de pertencimento a uma nação, conectando o individual ao planetário. Nesse sentido, a experiência coletiva materializa uma coletividade simbólica ao reunir distintos telespectadores em torno do mesmo conteúdo televisivo (SILVERSTONE, 1994).

Entretanto, com a fragmentação da audiência causada pela popularização dos serviços de conteúdo on demand e pelas novas ${ }^{6}$ formas de distribuição, o telespectador vem se distanciando do appointment television. ${ }^{7}$ Dessa forma, como a social TV é caracterizada pelo

5 Nos Estados Unidos, o hábito de socializar com os amigos, familiares e colegas de trabalho por meio da discussão informal sobre a programação televisiva é conceituado como watercooler. O termo faz alusão aos ambientes corporativos, principalmente escritórios, onde os funcionários se reuniam em torno do bebedouro para comentar o que tinham assistido na noite anterior (BENTON e HILL, 2012).

6 Tais como disponibilização dos episódios pelo YouTube, gravação dos programas por meio de equipamentos fornecidos pelas operadoras de TV por assinatura e de HDs das Smart TVs.

7 TV com hora marcada, assistir ao programa no seu horário original de exibição. 
compartilhamento de conteúdo de maneira síncrona ao fluxo televisivo, o fenômeno resgata a experiência coletiva. Conforme pontua Jost (2011, p. 102),

[h]oje em dia, os sites de redes sociais é que permitem a garantia de que vemos a mesma coisa, numa mesma época em que, por causa da multiplicidade de canais, não se pode dizer isso naturalmente. [...] Finalmente, as redes sociais contribuem a elaborar essas comunidades imaginárias às quais a televisão nos tinha habituado e estavam em vias de desaparecer.

O telespectador pode até assistir ao programa individualmente, mas, ao acessar redes sociais e os aplicativos de segunda tela, estará conectado a vários espectadores que, assim como ele, também estão acompanhando, naquele momento, a mesma atração.

\section{Twitter: o watercooler digital}

De acordo com a Nielsen (2016), o Twitter é a rede social mais usada pelos telespectadores interagentes ${ }^{8}$ estadunidenses na postagem de conteúdos relacionados à programação televisiva. Em 2015, 68\% dos 310 milhões de usuários ativos do microblogging tuitaram sobre o que estavam assistindo no momento (TV SEASON, 2016). Wolk (2015, p. 67) pontua que a forte adesão da rede social no âmbito da social TV não é por acaso: "O Twitter sempre foi a plataforma óbvia para a social TV. É pública, é sucinta e é fácil de organizar as publicações em torno de um tópico usando as hashtags" (tradução nossa). ${ }^{9}$

Os aspectos ressaltados pelo autor podem ser observados nas principais características da arquitetura informacional do Twitter. A interação social do microblogging é baseada na temporalidade always on, "[...] em que o passado importa pouco, o futuro chega rápido e o presente é onipresente" (SANTELLA e LEMOS, 2010, p. 61). Nesse sentido, a rede social propicia o compartilhamento instantâneo de informações, em

8 De acordo com Primo (2003, p. 8), o interagente é aquele que “[...] emana a ideia de interação, ou seja, a ação (ou relação) que acontece entre participantes".

9 "Twitter has always been the obvious platform for social TV. It's public, it's short and it's easy to organize tweets around a topic using hashtags." 
que só o “agora” interessa. De acordo com Santaella e Lemos (2010), essa temporalidade instantânea é uma característica exclusiva da rede social e faz com que as postagens se propaguem rapidamente pela rede. "A conversação e a discussão de ideias em tempo real são os principais diferenciais no uso dessa mídia” (SANTAELLA e LEMOS, 2010, p. 79).

Na social TV, essa dinâmica veloz do Twitter vai ao encontro do fluxo unilateral e regular da televisão. Cannito (2010, p. 49) afirma que a linguagem da TV é caracterizada pela reprodução ininterrupta de conteúdo e de modo independente do telespectador. Nesse sentido, a social TV aglutina dois presentes contínuos: a temporalidade always on do Twitter e a forma de distribuição da televisão. O usuário pode até relatar eventos antigos no microblogging ou gravar um programa para assistir no horário que lhe for mais conveniente, mas isso não descaracteriza a linguagem específica desses meios. Como a social TV se refere ao compartilhamento de conteúdos de maneira síncrona à exibição da grade de programação, o Twitter é a plataforma que melhor corresponde a esse fator, pois os telespectadores interagentes podem repercutir suas impressões em tempo real.

Outra característica da arquitetura informacional que contribui para que o microblogging seja a plataforma central do fenômeno é o foco da interação social. Ao contrário de redes sociais como, por exemplo, o Facebook e o extinto Orkut, as conexões “[...] no Twitter não são baseadas em vínculos preexistentes, mas sim na penetração individual em fluxos de ideias, ou seja, fluxos coletivos abertos de ideias compartilhadas em tempo real, que estão em movimento contínuo" (SANTAELLA e LEMOS, 2010, p. 91). Em outras palavras, no Twitter, as interações sociais não se restringem aos vínculos familiares, profissionais e de amizade. De acordo com Recuero (2014, p. 132), esse aspecto faz com que o Twitter propicie a formação de conexões assimétricas, aquelas que não dependem essencialmente da reciprocidade na criação de interações. Dessa forma, é possível "seguir" um usuário sem que este o "siga" de volta. O foco da interação social do Twitter contribui para a pluralidade 
do backchannel: ${ }^{10}$ ao acessar o microblogging, os telespectadores interagentes podem repercutir a atração que está no ar com interlocutores que vão além dos seus contatos pessoais. Nesse sentido, a arquitetura informacional do Twitter reforça não só a temporalidade da social TV, mas amplifica a conversação em torno da grade de programação.

\section{A social TV no âmbito das narrativas ficcionais seriadas estadunidenses}

Os canais estadunidenses ${ }^{11}$ começaram a usar massivamente o Twitter em 2008; inicialmente, a rede social tinha a função de divulgar as atrações da programação e retroalimentar os sites (WOHN, 2011). Já em 2009, as emissoras MTV e CNN passaram a estimular o backchannel durante a exibição de seus programas. Porém, a social TV só se popularizou, de fato, no âmbito televisivo em 2011 (PROULX e SHEPATIN, 2012).

Considerada por Proulx e Shepatin (2012, p. 11-12) o marco zero do fenômeno, a edição do Video Music Awards fomentou o diálogo entre o Twitter e o appointment television. Resultado de uma grande ação de marketing que envolvia parceria com o GetGlue ${ }^{12}$ e conteúdo exclusivo para a rede social, a premiação gerou, durante sua exibição, no dia 28 de agosto de 2011, 5.482 .861 milhões de tuítes (STATE OF THE MEDIA TRENDS, 2011). Apenas na apresentação da cantora Beyoncé, foi registrado um fluxo de 8.868 mil comentários por segundo, atingindo uma marca até então inédita (STATE OF THE MEDIA TRENDS, 2011).

10 Canal secundário de compartilhamento de conteúdo (texto, imagem, vídeo etc.) formado especificamente durante a exibição de um programa (PROULX e SHEPATIN, 2012).

11 No Brasil, a popularização da social TV se deu por meio da telenovela Avenida Brasil (Rede Globo, 2012). O folhetim mobilizou milhares de telespectadores interagentes no Twitter - apenas no último capítulo da trama, foram postados 108 mil tuítes na rede social. Atualmente, as ações desenvolvidas pelas emissoras nacionais para estimular o backchannel exploram desde aplicativos de segunda tela até parcerias com o Twitter Brasil na criação de estratégias direcionadas (BRANDÃO et al., 2015, p. 409-411; SIGILIANO e BORGES, 2016). De acordo com o Kantar Ibope Media (2015), 42\% dos telespectadores brasileiros compartilham conteúdos nas redes sociais de maneira síncrona à exibição da grade de programação. Entre os formatos mais comentados no Twitter estão os reality shows, os programas de auditório e as telenovelas.

12 Aplicativo de segunda tela. 
Todo o buzz $z^{13}$ gerado durante o evento fez com que os canais estadunidenses notassem a relevância do fenômeno no engajamento do público.

No âmbito das narrativas ficcionais seriadas estadunidenses, as ações de social TV vão além do simples estímulo ao appointment television. As estratégias possibilitam a expansão e o aprofundamento dos universos ficcionais e também a participação dos telespectadores interagentes (ANÁLISE, 2015-2016). Segundo Colletti e Materia (2012, p. 97-108), séries como, por exemplo, Grey's Anatomy (2005-atual, ABC), The Walking Dead (2010-presente, AMC) e Pretty Little Liars (2010-presente, ABC Family) promovem live chats no Twitter durante a exibição dos episódios. Além de comentarem os principais acontecimentos da temporada, os roteiristas e o elenco respondem as perguntas enviadas pelos telespectadores interagentes. Os perfis dos programas na rede social também disponibilizam conteúdos complementares como vídeos, fotos e emojis ${ }^{14}$ e estimulam a participação do público através da postagem de comentários, memes e montagens sobre a história.

A partir desse contexto, este artigo tem o objetivo de refletir sobre as ações de social TV adotadas pela Fox durante a $10^{\mathrm{a}}$ temporada de The $\mathrm{X}$-Files - isto é, como as postagens da página gerenciada pelo canal no Twitter contribuem para o aprofundamento e a compreensão do universo ficcional da série. Para a discussão dessas questões, analisaremos os tuítes publicados, de maneira síncrona à exibição dos episódios, pelo perfil (@ thexfiles $^{15}$ ) da trama na rede social.

\section{0 retorno de The $X$-Files}

Em meados da década de 1990, a Fox tentava se estabelecer na indústria televisiva estadunidense. Enquanto os canais NBC, CBS e ABC estavam preocupados com a fragmentação da audiência causada pela popularização da TV a cabo, a emissora investia na ampliação de sua

13 Segundo Trinta (2015, p. 4-5), no atual ecossistema de conectividade, buzz se refere a conteúdos que se propagam vertiginosamente pela rede.

14 Os emojis são desbloqueados quando o telespectador interagente usa uma determinada indexação proposta pelo canal. Ver Sigiliano, 2015.

15 Disponível em: https://twitter.com/thexfiles. Acesso em: 17 mar. 2017. 
grade de programação. Como observa Johnson (2005, p. 61), “[...] a Fox era um canal novo, as suas estratégias eram diferentes das adotadas pelas emissoras que já estavam estabelecidas há algum tempo"16 (tradução nossa). Após ter alcançado significativos índices de audiência com as séries Simpsons (1989-presente), Married... with Children (1987-1997) e Beverly Hills, 90210 (1990-2000), o canal estadunidense buscava uma série dramática para atrair o público de 18 a 49 anos (MITTELL, 2010). Segundo Reeves, Rodgers e Epstein (1996), a Fox visava atingir a faixa etária dos programas Roseanne (1988-1997, ABC), Home Improvement (1991-1999, ABC) e Mystery Science Theater 3000 (1988-1999, Comedy Central); entretanto, os formatos dessas produções exigiam custos que estavam além do orçamento do canal.

Depois de um longo processo de pilot season, ${ }^{17}$ a Fox decidiu produzir duas atrações, The X-Files (1993), de Chris Carter, e The Adventures of Brisco County (1993), de Jeffrey Boam e Carlton Cuse. Os programas competiam diretamente com a grade de sitcoms da $\mathrm{ABC}$, exibida às sextas-feiras a partir das 20 horas (JOHNSON, 2005). Apesar de ambas as séries apresentarem elementos de ficção científica, The Adventures of Brisco County foi cancelada pela Fox logo após a exibição de sua primeira temporada em decorrência dos baixos índices de audiência. Já The X-Files rapidamente chamou atenção do público: o episódio de estreia foi assistido por 12 milhões de telespectadores (PORTER e PORTER, 2010, p. 15-21).

A trama de The X-Files é centrada nos agentes do FBI Fox Mulder (David Duchovny) e Dana Scully (Gillian Anderson). Os personagens investigam casos não solucionados envolvendo fenômenos paranormais e/ou sem explicação científica, conhecidos como $x$-files. Porém, à medida que as investigações avançam, Mulder e Scully descobrem uma rede de conspiração envolvendo o governo estadunidense. A série foi exibida

16 "As a consequence of Fox's position as new network, the production strategies that it adopted differed from those of the three established networks."

17 Segundo Bennett (2014, p. 64-68), o pilot season é um sistema de pitch anual em que os criadores, produtores e roteiristas de ficção seriada se reúnem com emissoras e estúdios para apresentarem seus projetos. 
até 2002, totalizando nove temporadas com 201 episódios produzidos. $\mathrm{O}$ universo ficcional do programa também foi expandido através de HQs, livros, videojogos, filmes - The X-Files: Fight The Future (1998) e The X-Files: I Want to Believe (2008) - e do spin-off The Lone Gunmen (2001).

Em julho de 2013, a Comic-Con convidou os protagonistas de The X-Files e os roteiristas Vince Gilligan, Howard Gordon, Darin Morgan, John Shiban, James Wong, David Amann, Glen Morgan e Chris Carter para participarem de um painel comemorativo dos 20 anos de estreia da série (FOUTCH, 2013). O evento realizado em San Diego, na Califórnia, colocou o programa novamente em evidência e acabou chamando atenção da Fox. "Recebi uma ligação dos CEOs do canal, Dana Walden e Gary Newman, falando que estavam pensando em produzir novamente a série", ${ }^{18}$ pontua Chris Carter (CARTER, 2016).

A proposta da emissora era seguir os moldes de produção e distribuição adotados em 24: Live Another Day. Exibida pela Fox em 2014, a trama de Jack Bauer (Kiefer Sutherland) apresentava uma lógica de desenvolvimento proveniente da TV paga, isto é, em vez de ter uma temporada composta por 24 episódios, foram produzidos apenas 12 . O formato fez com que o retorno de The X-Files se tornasse viável e atraente para o elenco e para a equipe técnica.

Durante uma convenção anual de programação em março de 2015, 13 anos após a exibição do series finale,$^{19}$ a Fox anunciou o retorno de The X-Files. A 10a temporada da série, exibida nos Estados Unidos entre janeiro e fevereiro de 2016, foi composta por seis episódios.

\section{Monitoramento e análise das ações de engajamento de The X-Files na social TV}

Antes de analisarmos as ações de social TV realizadas pela Fox na $10^{\mathrm{a}}$ temporada de The X-Files, é importante detalharmos a abordagem metodológica de monitoramento usada neste artigo. A coleta dos tuítes postados pelo perfil @thexfiles durante a exibição dos episódios

18 Transcrição do áudio do DVD Arquivo X - uma série de casos (CARTER, 2016).

19 Último episódio da série. 
My Struggle, Founder's Mutation, Mulder and Scully Meet the Were-Monster, Home Again, Babylon e My Struggle II consistiu em uma combinação de procedimentos de observação e mineração dos dados gerados no Twitter de maneira síncrona à grade de programação (ZUELL e PRERADOVI $\square, 2013$; SIGILIANO e BORGES, 2016). Nesse contexto, o pertinente é a análise qualitativa dessas publicações, já que a quantitativa indicaria, por exemplo, o número de comentários, de compartilhamentos etc.

Semanalmente, entre os dias 24 de janeiro e 22 de fevereiro de 2016, foi realizado o monitoramento do perfil da série no Twitter. As publicações feitas pela página de The X-Files foram projetadas no Tweet Deck. ${ }^{20}$ O aplicativo nativo do microblogging possibilitou a captura dos tuítes pelo software Snagit. ${ }^{21}$ Dessa forma, cada publicação feita durante a exibição dos episódios foi armazenada.

Posteriormente, realizamos a mineração dos 463 tuítes gerados pela Fox. A filtragem individual das publicações indicou que, do total, 372 postagens eram menções a outras páginas na rede social e 91 eram tuítes sem menção. A partir dessa mineração, delimitamos o corpus de análise de 463 postagens e correlacionamos as publicações com os arcos narrativos exibidos nos episódios da $10^{\text {a }}$ temporada de The X-Files e com o universo ficcional do programa.

Enquanto a $10^{\mathrm{a}}$ temporada estava no ar, o perfil de The X-Files no Twitter desenvolveu várias ações de social TV, tais como a publicação de tuítes que ressaltavam o laço social e incentivavam a propagação e a produção de conteúdos, a troca de mensagens com os telespectadores interagentes e a realização de bate-papos com o elenco da série. As estratégias da Fox também abarcavam a postagem de tuítes que, além de enfatizar e ressignificar o universo ficcional, estimulavam a leitura atenta do público.

Os conteúdos postados pelo @thexfiles durante os episódios reforçavam a experiência coletiva e estimulavam o backchannel. Norteadas

20 Disponível em: https://tweetdeck.twitter.com/. Acesso em: 17 mar. 2017.

21 Disponível em: https://www.techsmith.com/screen-capture.html. Acesso em: 17 mar. 2017. 
por frases como "let's watch together", "we're all watching The X-Files together", "watching with us" e "all together",22 as publicações do perfil chamavam atenção para o laço social, ressaltando o sentido de presença do meio. Wolton (1996) afirma que a noção de laço social foi formulada por Durkheim e pela escola francesa de sociologia. Segundo o autor, as discussões em torno do conceito tinham uma perspectiva voltada para as práticas sociais institucionalizadas (trabalho, educação, família etc.). Posteriormente, a noção de laço social foi utilizada e ampliada pela antropologia cultural e, nesse âmbito, a televisão é um dos principais exemplos.

Wolton (1996) pontua que a TV generalista constitui um laço social em dois sentidos. O primeiro se refere ao fato "[...] de que o espectador, ao assistir televisão, agrega-se a esse público potencialmente imenso e anônimo que a assiste simultaneamente, estabelecendo assim, como ele, uma espécie de laço invisível” (WOLTON, 1996, p. 124). Esse laço silencioso cria um conhecimento comum (common knowledge) entre os telespectadores e entre as diferentes comunidades que constituem uma sociedade. Já o segundo sentido aponta que a TV é o "espelho da sociedade". Nesse contexto, “[...] a televisão cria não apenas uma imagem e uma representação, mas oferece um laço a todos aqueles que a assistem simultaneamente" (WOLTON, 1996, p. 124).

Entretanto, apesar de surgir no ambiente de convergência, a social TV potencializa o laço silencioso e invisível da televisão ao entrelaçar a temporalidade always on do Twitter e o fluxo televisivo. Isto é, se Wolton (1996), o fenômeno reforça esse aspecto da televisão, tão enfraquecido pelo consumo individual e pela fragmentação da audiência. Nesse sentido, ao ressaltar a experiência coletiva nos tuítes, a Fox fortalece o laço social.

Para ajudar na propagação do conteúdo, a página pedia que os telespectadores interagentes retuitassem (RT) a mensagem com os dizeres: "this person is watching The X-Files". Dessa forma, o público não só

22 "Vamos assistir juntos", "Todos estamos assistindo The X-Files juntos", "Assista com a gente", "Todos juntos" (tradução nossa). 
divulgava na sua timeline que o programa estava no ar, mas podia, mesmo que indiretamente, influenciar seus seguidores a ligarem a TV.

O estímulo ao backchannel permeou as ações de engajamento no Twitter de todos os episódios da $10^{\text {a }}$ temporada da atração. À medida que as cenas eram exibidas, o perfil @thexfiles incentivava os telespectadores interagentes a compartilhar memes, fotos, vídeos e, principalmente, comentários enquanto assistiam à trama.

Figura 1. O perfil oficial da série The X-Files ressalta a experiência coletiva da televisão e estimula os telespectadores interagentes a compartilhar suas impressões durante a exibição do episódio.

\section{(X) The X-Files}

We're all watching \#TheXFiles together! All time zones! So get ready...we're starting soon.

$$
\text { Traduzido do inglês }
$$

(X) The X-Files

Here we go! Episode 2 of \#TheXFiles starts now! Traduzido do inglês

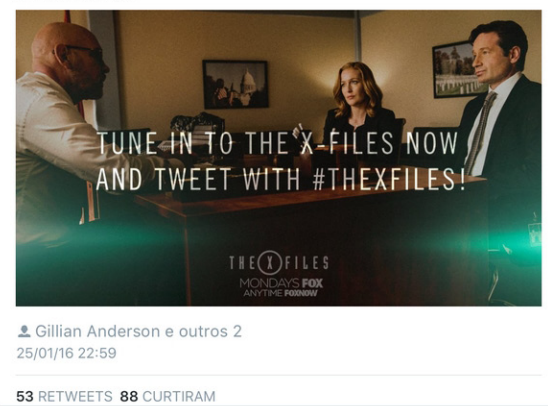

477 RETWEETS 732 CURTIRAM

Fonte: Dados da pesquisa (2016).

Porém, um dos pontos mais relevantes da estratégia de social TV do @thexfiles era o diálogo que o perfil conseguia estabelecer com o público. Em vez de apenas incentivar a conversação em torno do programa, a página trocava mensagens com os telespectadores interagentes sobre distintos assuntos. Além de informar os horários de reprise e detalhes da sinopse, o @thexfiles respondia dúvidas relacionadas aos arcos narrativos e aos futuros acontecimentos da história. As publicações eram feitas em tempo real e de forma personalizada, isto é, cada menção continha um texto diferente, se distanciando de posts mecânicos e agendados. 
Figura 2. O perfil oficial da série The X-Files troca tuítes com os telespectadores interagentes durante a exibição dos episódios da $10^{\mathrm{a}}$ temporada.

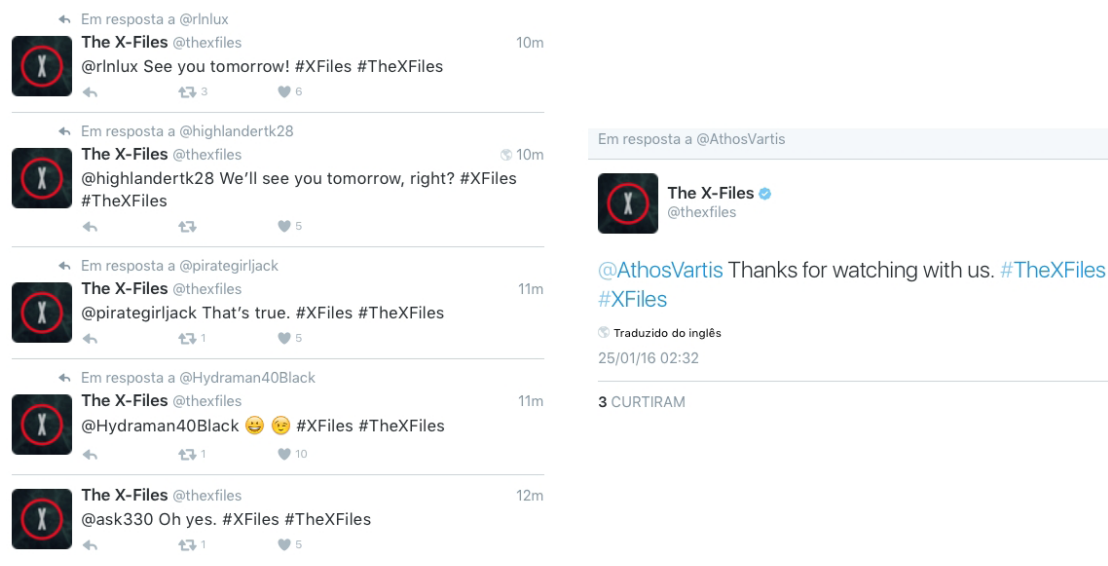

Fonte: Dados da pesquisa (2016).

Os atores Gillian Anderson ${ }^{23}$, David Duchovny ${ }^{24}$ e Mitch Pileggi25 também contribuíram para a pluralidade do watercooler de The X-Files. Por meio de suas contas pessoais no microblogging, o elenco conversava com os seguidores sobre a nova temporada. Nesse sentido, a ação da Fox não só estabelecia um diálogo com os telespectadores interagentes, mas estimulava o appointment television. Ou seja, o público poderia até optar por assistir ao programa no horário que lhe fosse mais conveniente, mas perderia a oportunidade de trocar tuítes com o elenco e tirar suas dúvidas sobre a série.

Além de se distanciar de uma comunicação unilateral, o perfil da trama no Twitter valorizava as postagens do público. Durante a exibição dos seis episódios inéditos, algumas postagens dos telespectadores interagentes eram retuitadas. As publicações abrangiam desde elogios à atração até memes ${ }^{26}$ envolvendo as temáticas da história.

23 Disponível em: https://twitter.com/GillianA. Acesso em: 19 mar. 2017.

24 Disponível em: https://twitter.com/davidduchovny. Acesso em: 19 mar. 2017.

25 Disponível em: https://twitter.com/MitchPileggil. Acesso em: 19 mar. 2017.

26 Segundo Gleick (2013, p. 17), o meme é "um replicador e um propagador - uma ideia, uma moda, uma corrente de correspondência". 
Norteada por uma complexa narrativa, The X-Files teve seu universo ficcional detalhado na segunda tela. Os conteúdos que integravam as ações de social TV do programa ajudavam na compreensão dos plots ${ }^{27}$ de My Struggle, Founder's Mutation, Mulder and Scully Meet the Were-Monster, Home Again, Babylon e My Struggle II. Durante a exibição dos episódios, o perfil da série no Twitter ressaltava os principais arcos das tramas por meio de fotos, GIFs e enquetes.

As fotos eram sempre acompanhadas de falas e/ou diálogos das cenas - nesse contexto, a frase destacada pelo @thexfiles reproduzia um momento importante da história que iria influenciar diretamente no desenrolar da narrativa. Já os GIFs chamavam atenção para os plots centrais da temporada, como, por exemplo, o reencontro de Mulder (David Duchovny) e Scully (Gillian Anderson), o paradeiro de William, os detalhes das investigações e até os elementos característicos do universo ficcional de The X-Files. Ou seja, pontos recorrentes da atração que sempre integraram os episódios, como o tema de abertura, as lanternas, as frases "Mulder it's me", "But Scully, aliens" e os lápis fincados no teto do escritório. As postagens funcionavam como uma espécie de guia para o telespectador interagente, indicando os acontecimentos mais representativos do programa.

Outra estratégia adotada pelo perfil da atração no Twitter foi a apresentação dos novos personagens da $10^{a}$ temporada. Cada aparição de Tad O’Malley (Joel McHale) e Sveta (Sheila Larken) em My Struggle e My Struggle II era ressaltada pelo @thexfiles. Os tuítes continham a foto e o nome do personagem que estava em cena e ajudavam o público a se familiarizar com os novos arcos da trama. Também foram criadas enquetes que problematizavam a índole de Tad e Sveta, cujas opções chamavam atenção para os motivos que levaram os personagens a tomarem certas decisões e facilitavam o entendimento do telespectador interagente.

Porém, as ações de social TV criadas pela Fox para a $10^{a}$ temporada de The X-Files não se limitavam ao universo ficcional da trama. Algumas

27 História da série ou da temporada ligada ao principal arco narrativo. 
Figura 3. As postagens do perfil oficial da série The X-Files ressaltam o diálogo entre Scully (Gillian Anderson) e Tad O’Malley (Joel McHale) - arco que é apresentado no episódio My Struggle e influencia diretamente a season finale da série - e as emblemáticas lanternas dos agentes do FBI, respectivamente.

\section{(X) The X-Files 0}

Can't a woman test herself for alien DNA without being bothered? \#TheXFiles

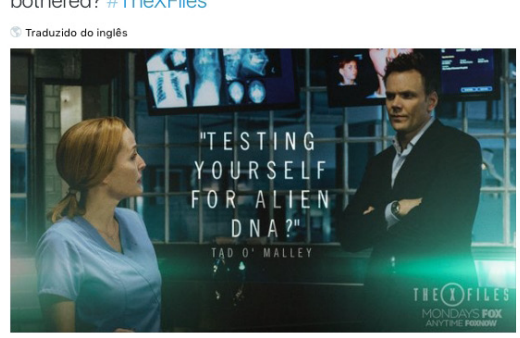

25/01/16 01:50

456 RETWEETS 1.135 CURTIRAM

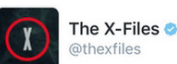

Flashlights! \#TheXFiles

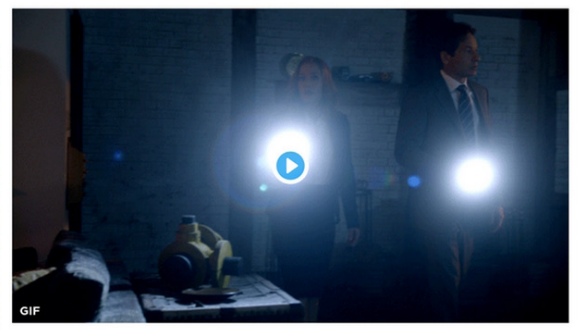

$25 / 01 / 1623: 15$

167 RETWEETS 299 CURTIRAM

Fonte: Dados de pesquisa (2016).

cenas foram ressignificadas pelo @thexfiles - o perfil destacava uma imagem que estava no ar, mas a colocava em outro contexto. Como, por exemplo, o tuíte publicado durante a exibição de Founder's Mutation.

A postagem mostrava Sanjay (Chris Logan) tendo um surto psicótico; entretanto, se, no episódio, o personagem é vítima de um experimento genético, no meme, o perfil fazia uma alusão ao excesso de cafeína. Com os dizeres "Us after too much coffee", ${ }^{28}$ a página satirizava o comportamento de Sanjay (Chris Logan) ao relacionar sua agitação aos efeitos causados pelo consumo do composto químico em grandes quantidades.

O uso de memes ajudava na propagação dos tuítes do perfil da trama ao explorar situações corriqueiras do dia a dia, tais como a rotina desgastante de trabalho, o engarrafamento das grandes cidades e o excesso de café. As publicações também chamavam atenção de usuários que não estavam acompanhando a série, mas que se identificavam com o contexto.

28 "Nós depois de muito café" (livre tradução nossa). 
Figura 4. O perfil de The X-Files ressignifica a cena do episódio Founder's Mutation.

\section{Us after too much coffee. \#TheXFiles}

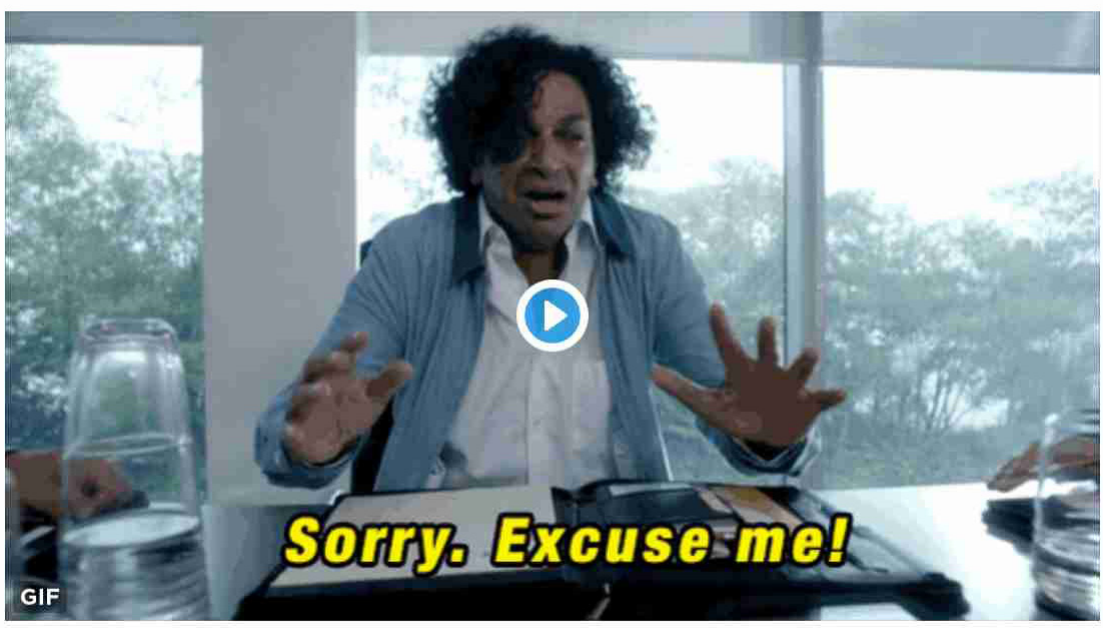

\section{5/01/16 23:03}

\section{RETWEETS 193 CURTIRAM}

Fonte: Dados da pesquisa (2016).

Além disso, a página de The X-Files no Twitter estimulava a leitura atenta dos telespectadores interagentes. Os arcos narrativos da série foram permeados pelas referências ao universo ficcional e pelas intertextualidades. Nesse contexto, o perfil da atração pedia que o público compartilhasse os easter eggs ${ }^{29}$ presentes nos episódios.

A estratégia de engajamento do canal Fox possibilitava, mesmo que indiretamente, a formação de arcabouços informacionais em torno

29 Os easter eggs são pequenas referências, alusões, informações, piadas e/ou conteúdos mostrados de maneira oculta em softwares, séries, filmes, videojogos etc. (CLARKE, 2010). 
desses elementos da história. Ao clicar no tuíte do perfil do programa, era possível visualizar todas as respostas enviadas a partir da publicação do @thexfiles. Dessa forma, os telespectadores interagentes tinham acesso às novas perspectivas da $10^{\mathrm{a}}$ temporada. Apesar de não serem fundamentais para o entendimento dos episódios, os easter eggs ampliavam o significado das cenas. Como, por exemplo, em Mulder and Scully Meet the Were-Monster, quando Mulder (David Duchovny) se aproxima de um túmulo com a identificação Kim Manners. Dentro da trama, o nome não altera o curso de nenhum acontecimento, mas a intertextualidade é uma homenagem a um dos diretores de The X-Files que faleceu em 2009. O mesmo pode ser observado no plano de encerramento de Babylon, que faz uma alusão à última cena do longa-metragem I Want to Believe, lançado em 2008.

Em suma, as ações de social TV desenvolvidas pelo perfil da trama, @thexfiles, durante a $10^{\mathrm{a}}$ temporada de The X-Files vão além do simples estímulo ao appointment television. As publicações reforçam a experiência coletiva e o compartilhamento de conteúdos no Twitter de maneira síncrona à exibição dos episódios, contribuindo para a pluralidade do backchannel. Outro ponto importante nas estratégias adotadas pela emissora estadunidense é o diálogo com os telespectadores interagentes, isto é, cada menção ao perfil era prontamente respondida.

Os tuítes também ajudavam na compreensão do universo ficcional da série. À medida que os episódios iam ao ar, o @thexfiles destacava cenas e diálogos importantes no desdobramento dos arcos narrativos. Alguns momentos dos episódios eram ressignificados, dando origem a memes que ironizavam situações do cotidiano. Por fim, o perfil da atração no microblogging incentivava a leitura atenta do público, destacando os easter eggs que permeavam a trama.

Dessa forma, as ações do canal no âmbito da social TV potencializam o laço social, chamando atenção para a comunidade imaginada formada a partir do fluxo televisivo, além de contribuírem para o aprofundamento e a expansão do universo ficcional de The X-Files. Nesse contexto, as estratégias de engajamento estimularam o buzz em torno 
Figura 5. O perfil de The X-Files pede que os telespectadores compartilhem os easter eggs presentes no episódio. Ao clicar no tuíte, é possível acessar as respostas do público.

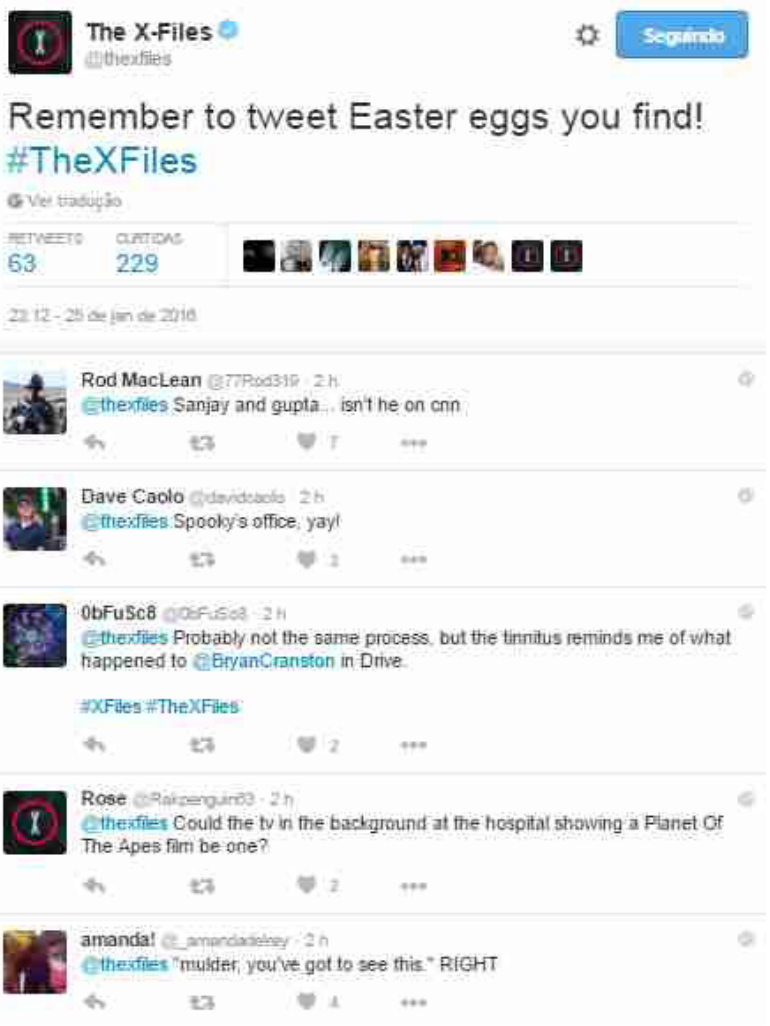

Fonte: Dados da pesquisa (2016).

dos episódios: durante a exibição da série, foram postados cerca de 85 mil tuítes e a indexação \#thexfiles ficou três vezes no trending topics ${ }^{30}$ mundial. De modo geral, os conteúdos compartilhados pelos telespectadores interagentes repercutiam as cenas que estavam no ar, refletiam sobre os desdobramentos dos arcos narrativos e ressaltavam as principais temáticas abordadas nos episódios através de memes, montagens e GIFs (SIGILIANO, 2017).

30 Assuntos do momento. 


\section{Considerações finais}

As publicações feitas pelo canal Fox durante a $10^{\mathrm{a}}$ temporada de The X-Files ressaltavam o laço social; nesse sentido, ao acompanhar os tuítes, os telespectadores interagentes se sentiam parte de uma atividade coletiva, planetária. Outro ponto importante na estratégia da emissora é a maneira como o perfil @thexfiles estimulou e agregou os conteúdos produzidos pelo público. Essa postura cooperativista da página não só impulsionava o backchannel, mas possibilitava que o universo ficcional fosse abordado a partir de várias perspectivas.

Para incentivar o appointment television, o elenco da trama promoveu live chats no Twitter. Os atores Gillian Anderson, David Duchovny e Mitch Pileggi trocavam mensagens com os telespectadores interagentes e comentavam a atração. O diálogo também se estendeu ao @thexfiles: durante os episódios, o perfil da série respondia dúvidas do público sobre os arcos narrativos, horários de reprise, participações especiais etc. Porém, cada tuíte enviado pela página era distinto, isto é, as respostas não consistiam em textos pré-programados, pelo contrário, a interação variava de acordo com o interlocutor.

As ações de social TV do canal Fox para a $10^{a}$ temporada de The X-Files contribuíram diretamente para a compreensão dos episódios da trama. À medida que a cenas eram exibidas, o perfil ressaltava pontos específicos da história com fotos, GIFs e textos e também apresentava os novos personagens da série. Nesse sentido, os conteúdos funcionavam como uma espécie de guia para os complexos e imbricados arcos narrativos do programa. A página da atração no Twitter também ressignificou os acontecimentos dos episódios, criando memes que ironizavam alguns hábitos do dia a dia. Por fim, o perfil da trama estimulou a leitura atenta dos telespectadores interagentes, pedindo que o público enviasse os easter eggs presentes nas sequências da atração.

A partir da análise das estratégias de social TV desenvolvidas para a $10^{\mathrm{a}}$ temporada de The X-Files, conclui-se que o canal Fox foi além do simples incentivo ao appointment television. Isto é, cada tuíte tinha uma função no backchannel, seja na compreensão do complexo universo 
ficcional, na fidelização do público através dos live chats ou no aprofundamento da trama. A postura da emissora não só vai ao encontro do ambiente de convergência midiática e da cultura participativa, mas ressalta a importância da segunda tela no âmbito das narrativas ficcionais seriadas.

Nesse contexto, a social TV passa a funcionar como um suporte para os densos universos ficcionais da post-network television ao estabelecer essa sinergia com os arcos narrativos da $10^{\mathrm{a}}$ temporada de The X-Files. Isto é, a segunda tela atua como um prolongamento da série que está no ar, contribuindo para o aprofundamento e detalhamento da trama. Entretanto, é fundamental que os tuítes que reforçam e detalham o universo ficcional não distanciem os telespectadores interagentes do exercício cognitivo de desmembrar essas histórias. Afinal, a profundidade dos arcos narrativos e a forma como eles demandam a leitura atenta do público são aspectos centrais das séries contemporâneas.

\section{Referências}

ANÁLISE. Observatório da Qualidade do Audiovisual, 2015-2016. Disponível em: http://observatoriodoaudiovisual.com.br/resultados/social-tv/analise-2/. Acesso em: 18 mar. 2017.

ANDERSON, B. Comunidades Imaginadas - reflexões sobre a origem e a difusão do nacionalismo. São Paulo: Companhia das Letras, 2008.

BENNETT, T. Showrunners: the art of running a TV show. Londres: Titan Books, 2014. BENTON, A.; HILL, S. The Spoiler Effect? Designing Social TV Content That Promotes Ongoing WOM. In: CONFERENCE ON INFORMATION SYSTEMS AND TECHNOLOGY. Anais... Arizona, 2012.

BORGES, G.; SIGILIANO, D. Television dialogues in Brazilian fiction: between production and consumption. Applied Technologies and Innovations, v. 12, n. 2, p. 54-68, 2016. Disponível em: https://academicpublishingplatforms.com/article.php?journal=A TI\&number=20\&article=2288. Acesso em: 21 maio 2017.

BRANDÃO, M. C. ET AL. Cultura participativa na esfera ficcional de O Rebu. In: LOPES, M. I. V. (Org.). Por uma teoria de fãs da ficção televisiva brasileira. Porto Alegre: Sulina, 2015. p. 339-347. 
CANNITO, N. A televisão na era digital - interatividade, convergência e novos modelos de negócio. São Paulo: Plexus, 2010.

CARTER, C. Arquivo X - uma série de casos. Twentieth Century Fox Television, 2016. 3 DVDs, NTSC, color, Dolby Digital 5.1.

CLARKE, M. Lost and Mastermind Narration. Television New Media, v. 11, n. 2, p. 123-142, 2010. Disponível em: http://journals.sagepub.com/doi/ pdf/10.1177/1527476409344435. Acesso em: 9 jan. 2017.

COLLETTI; G.; MATERIA, A. Social TV. Guida alla nuova TV nell'era di Facebook e Twitter. Milão: Gruppo24Ore, 2012.

FECHINE, Y. TV Social, práticas interacionais e modos de presença: contribuição para a delimitação do conceito. In: XXV ENCONTRO ANUAL DA COMPÓS, 2016. Anais... Goiânia, 2016. Disponível em: http://www.compos.org.br/biblioteca/pdfformatsite_3428.pdf. Acesso em: 10 mar. 2017.

FOUTCH, H. Comic-Con 2013. Painel - 20 anos de Arquivo X. Omelete, 19 jul. 2013. Disponível em: https:/omelete.uol.com.br/series-tv/artigo/comic-con-2013-painel-20-anos-de-arquivo-x/. Acesso em: 15 mar. 2017.

JOHNSON, C. Quality/Cult Television: The X-Files and television history. HAMMOND, M; MAZDON, L. (Orgs.). The contemporary television series. Edimburgo: Edinburgh University Press, 2005. p. 57-74.

JOST, F. Novos comportamentos para antigas mídias ou antigos comportamentos para novas mídias? Matrizes, São Paulo, v. 4, n. 2, p. 93-109, 2011. Disponível em: www. revistas.usp. br/matrizes/article/download/38294/41119. Acesso em: 2 mar. 2017.

MITTELL, J. Television and American Culture. Nova York: Oxford University Press, 2010.

PORTER, B.; PORTER, L. The Adventures of Brisco County. In: LAVERY, D. (Org.). The essential cult TV reader. Kentucky: University Press of Kentucky, 2010. p. 15-21.

PRIMO, A. Quão interativo é o hipertexto? Da interface potencial à escrita coletiva. Fronteiras: Estudos Midiáticos, São Leopoldo, v. 5, n. 2, p. 125-142, 2003. Disponível em: http://www.ufrgs.br/limc/PDFs/quao_interativo_hipertexto.pdf. Acesso em: 7 mar. 2017.

PROULX, M.; SHEPATIN, S. Social TV - How marketers can reach and engage audiences by connecting television to the web, social media, and mobile. Nova Jersey: John Wiley \& Sons, 2012.

RECUERO, R. A conversação em rede: comunicação mediada pelo computador e redes sociais na Internet. Porto Alegre: Sulina, 2014.

REEVES, J. L.; RODGERS, M. C.; EPSTEIN, M. Rewriting Popularity - The Cult Files. In: LAVERY, D.; HAGUE, A.; CARTWRIGHT, M. (Orgs.). Deny All Knowledge - Reading the X-Files. Nova York: Syracuse University Press, 1996. p. 22-35.

REVELANDO o ambiente Social TV. Kantar Ibope Media, Artigos \& Papers, 2015. Disponível em: https:/www.kantaribopemedia.com/revelando-ambiente-social-tv/. Acesso em: $1^{\circ}$ jun. 2017. 
SANTAELLA, L.; LEMOS, R. Redes sociais digitais: a cognição conectiva do Twitter. São Paulo: Paulus, 2010.

SIGILIANO, D. Rede Globo investe em ação inédita para estimular o backchannel do The Voice Brasil. Observatório da qualidade no audiovisual, 2015. Disponível em: http:// observatoriodoaudiovisual.com.br/thevoicebrasilnasocialtv/. Acesso em: 5 mar. 2017.

Social TV: o laço social no backchannel de The X-Files. Dissertação (mestrado) - Universidade Federal de Juiz de Fora, Juiz de Fora, 2017.

.; BORGES, G. A Rede Globo no ecossistema da Social TV: uma análise sobre as postagens do perfil @redeglobo no Twitter. Intexto, Porto Alegre, n. 36, p. 103-120, 2016. Disponível em: http://seer.ufrgs.br/index.php/intexto/article/view/60315. Acesso em: 21 maio 2017

SILVERSTONE, Roger. Television and Everyday Life. Nova York: Routledge, 1994. STATE OF THE MEDIA TRENDS in TV Viewing - 2011 TV Upfronts. Nielsen, 2011. Disponível em: http://www.nielsen.com/content/dam/corporate/us/en/newswire/ uploads/2011/04/State-of-the-Media-2011-TV-Upfronts.pdf. Acesso em: 7 mar. 2017.

SUMMA, G. Social TV: the future of television in the Internet Age. Tese (mestrado em Management Studies). Massachusetts: Massachusetts Institute of Technology, Sloan School of Management, 2011.

TRINTA, A. R. Anotações de aula - Estética, Redes e Linguagens. Juiz de Fora: Universidade Federal de Juiz de Fora, 2015. Disponível em: https:/goo.gl/IclAAX. Acesso em: 11 mar. 2017.

TV SEASON 2015-2016 in review: the biggest social TV moments. Nielsen, 2016. Disponível em: http://www.nielsen.com/us/en/insight/news/2016/tv-season-2015-2016-in-review-the-biggest-social-tv-moments.html. Acesso em: 9 mar. 2017.

WOHN, Y. History of Social Television. D. Yvette Wohn. Technology, Media, and Digital Life, 11 jan. 2013. Disponível em: http://yvettewohn.com/2013/01/11/history-of-social-television/. Acesso em: 10 mar. 2017.

WOLK, A. Over the top - How the internet is (slowly but surely) changing the television industry. Nova York: CreateSpace, 2015.

WOLTON, D. Elogio do grande público. Uma teoria crítica da televisão. São Paulo: Ática, 1996.

ZUELL, B.; PRERADOVIĆ, N. M. Methods and usage of sentiment analysis in the context of the TV industry. Recent Advances in Information Science, [s.d.]. Disponível em: http://www.wseas.us/e-library/conferences/2013/Dubrovnik/ECC/ECC-19.pdf. Acesso em: 14 mar. 2017. 


\section{Sobre os autores}

Daiana Sigiliano - Mestre em comunicação pela Universidade Federal de Juiz de Fora. Membro do grupo do Grupo de Pesquisa em Redes, Ambientes Imersivos e Linguagens da Universidade Federal de Juiz de Fora e do Grupo de Pesquisa em Tecnologia, Comunicação e Ciência Cognitiva da Universidade Federal do Amapá. Pesquisadora da Rede Obitel (Equipe UFJF) e da Rede de Pesquisa Aplicada Jornalismo e Tecnologias Digitais (JorTec).

Gabriela Borges - Mestre e Doutora em Comunicação e Semiótica pela PUC-SP, com estágios na Universidade Autônoma de Barcelona, Dublin Trinity College e Universidade do Algarve. Pós-doutora pela Universidade do Algarve em Portugal. Professora e coordenadora do Programa de Pós-Graduação em Comunicação da Universidade Federal de Juiz de Fora. Pesquisadora da rede Obitel Brasil/UFJF.

Data de submissão: 07/04/2017

Data de aceite: 27/04/2017 